\title{
Public and private health care utilization differences between socioeconomic strata in Jamaica
}

This article was published in the following Dove Press journal:

Patient Related Outcome Measures

I September 2010

Number of times this article has been viewed

\author{
Paul A Bourne' \\ Denise Eldemire-Shearer ${ }^{\prime}$ \\ Tomlin J Paul' \\ Janet LaGrenade' \\ Christopher AD Charles ${ }^{2}$ \\ 'Department of Community Health \\ and Psychiatry, Faculty of Medical \\ Sciences, University of the West \\ Indies, Mona, Kingston, Jamaica; ${ }^{2}$ King \\ Graduate School, Monroe College, \\ New York and Center for Victim \\ Support, Harlem Hospital Center, \\ New York, NY, USA
}

Objective: To assess trends in the use of private and public health care services among Jamaicans over a 15-year period (1991-2007).

Design and methods: Statistics on the use of health care services were taken from the Jamaica Survey of Living Conditions (JSLC) for the 15-year period 1993 to 2007. Use of hospital services were represented in income quintiles and compared for private and public facilities. The difference in percentage use between public and private was compared by quintiles over the period and the variability in those differentials assessed.

Results: This study highlights the increasing use of private services by increasing wealth, exaggerated for the wealthiest quintile. There is a widening of the differences in utilization between public and private centers as income level increases $(P<0.001)$.

Conclusions: Internal and external economic conditions influence the use of private and public health care services in Jamaica. Although the relative increase in the cost (to the user) of public health care is more than that for private health care, the actual cost to use the public health care system is still significantly cheaper than using the private system. Lower income health care users tend to take the lesser cost option.

Keywords: health care utilization, public-private health differentials

\section{Introduction}

Access to health care, and utilization of health care, is increasingly being identified as one of the most pressing challenges to the health care system, and by extension health policy, in many developing as well as some developed nations. ${ }^{1,2}$ This discussion is taking place against the background of increasing recognition of health as a human right, an important component of development and one of the main dimensions and factors in overall wellbeing. ${ }^{1}$ Regional health priority, according to Pan American Health Organization (PAHO) and Caribbean Community (Caricom), ought to focus on reducing health inequalities. ${ }^{3}$ While many factors contribute to the development of health inequalities, it is recognized that health care is one of the factors. ${ }^{1}$ Studies have also shown a relationship between socioeconomic differences and the use of health care services in several countries. ${ }^{4}$

The relative utilization of public and private health care varies markedly between countries.

Despite the higher cost of private health care in India for gynecological disorders, urological diseases, heart diseases, tuberculosis and diarrheal disorders, $58 \%$ of the patients in a national sample used private health care. ${ }^{5}$

On the other hand, the Australian health care system sees higher utilization of medical services compared to other OECD countries. ${ }^{6}$ However, Australians with higher
(

Dept of Community Health and

Psychiatry, Faculty of Medical Sciences,

University of the West Indies, Mona,

Kingston, Jamaica

Tel +l 8765123540

Email paulbournel@yahoo.com 
income are more likely to see specialists compared to their low income counterparts who see general practitioners and there is concern that Australians with different incomes do not get the same mix of medical services. ${ }^{6}$ In Western Australia, policies favoring private health insurance (PHI) modified patients' behavior by decreasing the move away from the private sector. Policy reforms have generated demand for health care because the increase use of PHI was partly a function of the demand of patients who were patients in public hospitals. ${ }^{7}$

The Norwegian public health system with expensive private care and free public health care is very revealing. ${ }^{8}$ One study found that the physicians working in dual practice create lower overall provision of health care because dual practice crowds out the provision of public services. Regarding solutions, the health authority can offer higher wages. Also a ban on dual practice works best if public and private care is relatively close substitutes and competition from the private sector is weak. However, in the case where private sector is strong, a pure national health system is inferior to a mixed system, ${ }^{8}$ and the interests of the various stakeholders should be taken into account.

In 2005 a majority of Canadian doctors voted in support of private insurance to cover necessary medical services that cannot be offered in a timely manner by the public system. The doctors have been accused of acting in their own self interests and there have been calls to support medicare and the public interests. ${ }^{9}$

In developing countries, the quality of private health care for low to middle income users can be enhanced by improving quality, preventing exploitative prices, and promoting wider access. ${ }^{10}$ These strategies can be buttressed by free service for targeted groups, community education, and accreditation programs. The effectiveness of these additional strategies is a function of the capabilities of stakeholders and the context in which they operate.

Sinclair showed convincing status differentials in the use of health centers and private general practice services between communities in Kingston, Jamaica. ${ }^{11}$ The extent of the differentials in use of public-private health care services are affected by the relative price of health care, which is dependent on the actual price and economic enabling factors such as health insurance. ${ }^{11}$ A positive correlation has been illustrated between health insurance coverage and utilization of private practitioner services in a low income Jamaican suburb, supporting the finding that public-private differentials are sensitive to affordability of health care services. ${ }^{12}$ The public-private differential in Jamaica is not just affected by socioeconomic status, government policy, and resource insufficiency; but also traditional spiritual beliefs influence health care utilization, particularly in rural Jamaica. ${ }^{13}$

Research shows the success of public-private partnerships to improve welfare and health services for a broad range of health problems in developing countries has been mixed. ${ }^{14}$

Therefore, research is needed to investigate the comparative effectiveness of public and private health systems in Jamaica. However, care should be taken that a data-driven investigation method does not ignore expert and personal medical opinion with the result of dehumanizing patients. The research needs to explicitly consider patient inputs and requirements during the interpretation, circulation and implementation of data for policy purposes. ${ }^{15}$

This paper examines the changes in the utilization of public and private health care services in Jamaica between 1988 and 2008 and contrasts these against changes in relevant economic variables impacting upon the actual and apparent costs of care and health insurance coverage.

\section{Aim}

To describe the relationship between use of public and private health service utilization over a fifteen year period.

\section{Specific objectives}

1. To determine the changes in use of public and private health care service utilization

2. To describe the effect of patient's having private health insurance on public-private health care utilization

3. To determine the relationship between economic variables and public-private health care utilization

\section{Design and methods}

Since 1988, the Statistical Institute of Jamaica in collaboration with the Planning Institute of Jamaica has been conducting annual studies of living conditions of Jamaicans. The outcomes of these yearly studies are published as the Jamaica Survey of Living Conditions ${ }^{21}$ (JSLC), and that survey constitutes the primary data source for this study.

The JSLC is an adaptation of the World Bank's Living Standard Measurement Study household survey, with some modifications as the JSLC focuses on and emphasizes policy impacts. The survey design is that of a multi-topic household survey including a section on health, consumption, education, household incomes, anthropometric measurements, and immunization data on all children 0-59 months, and other demographic variables on Jamaicans.

Self-administered questionnaires were used to collect the data, and these were then stored and analyzed using SPSS 
software (version 16.0; SPSS Inc; Chicago, IL, USA). The questionnaire covered areas such as sociodemographic, economic and health variables. The non-response rate for the survey was $26.2 \%$. Participants are asked to recall specific and detailed consumption patterns over the last 30 days of the survey period as well as their health care expenditure. The basic structure of the questionnaire has remained the same over the years with inclusive of additional modules covering social safety net, crime and victimization, physical environment, remittances, and others at different survey periods.

The data on utilization of health services is published annually as part of the (JSLC) and data for this study was obtained from the JSLC for the periods 1988 to 2007. Approximately 1800 questionnaires were analyzed each year.

The JSLC data is organized by quintiles of economic wellbeing. The quintiles were formed from sample household members after arranging them in ascending order of their per capita household consumption. Per capita consumption is arrived at by dividing the total household consumption by the number of household members. All members of the household are assumed to have the same per capita consumption.

Data were also obtained relating to the purchase of pharmaceuticals, visits to public health facilities and the related costs per prescription over the period. These data were extracted from the Jamaica, Ministry of Health's annual Report. ${ }^{22}$

The levels of poverty and consumption were extracted as were the reported costs of care in the public and private sectors and the levels of health insurance coverage.
Data analyses were accommodated by percentages, graphs, chi-square and Pearson's Product Moment Correlation. A $P$ value $<0.05$ (two-tailed) was used to establish statistical significance.

\section{Results}

Generally, more than $50 \%$ of persons reporting ill-health go on to seek health care (mean $=58.0 \% \pm 8.2 \%$ ), and this proportion is steadily increasing (Figure 1). The use of private health care facilities has declined over the period studied (Figure 2) and in 2002 the use of public health care facilities exceeded the use of private health care utilization. Furthermore, generally, in periods of high inflation, private health care utilization are higher than in periods of low inflation; and a strong positive correlation existed between prevalence of poverty and inflation $(\mathrm{r}=0.856, P<0.0001)$.

Using the mean expenditure on public and private health care services by individuals in Jamaica (at 1990 prices), overall, the mean public health care expenditure has been increasing more than the inconsistent movements in the mean private health care expenditure for 1989-2007 (Figure 3). Furthermore, Figure 3 shows steeper rises and falls in mean private health care expenditure compared to the mean public health care expenditure. In addition to the aforementioned, from 1989-2007, Figure 3 shows public to have increased by $263 \%$ compared to a $15 \%$ increase in mean health care expenditure for private services, and there were some period where the percentages were considerably larger than from 1989-2007.

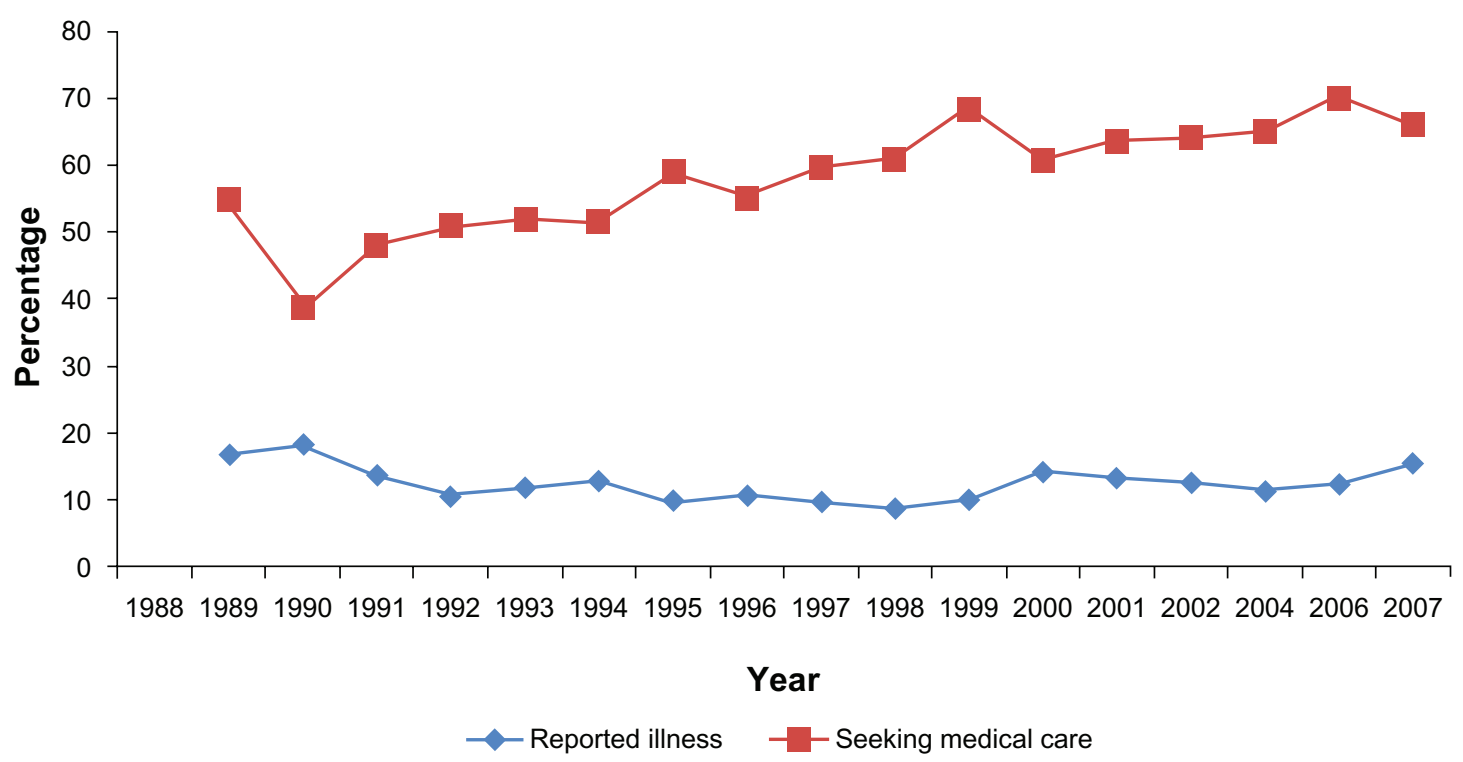

Figure I Self-reported IIIness and those seeking medical care 1988-2007.

Note: "Seeking medical care" is the proportion of those experiencing illness who then went to public or private medical care facilities (self-reported data). Data taken from Jamaica Survey of Living Conditions. ${ }^{21}$ 


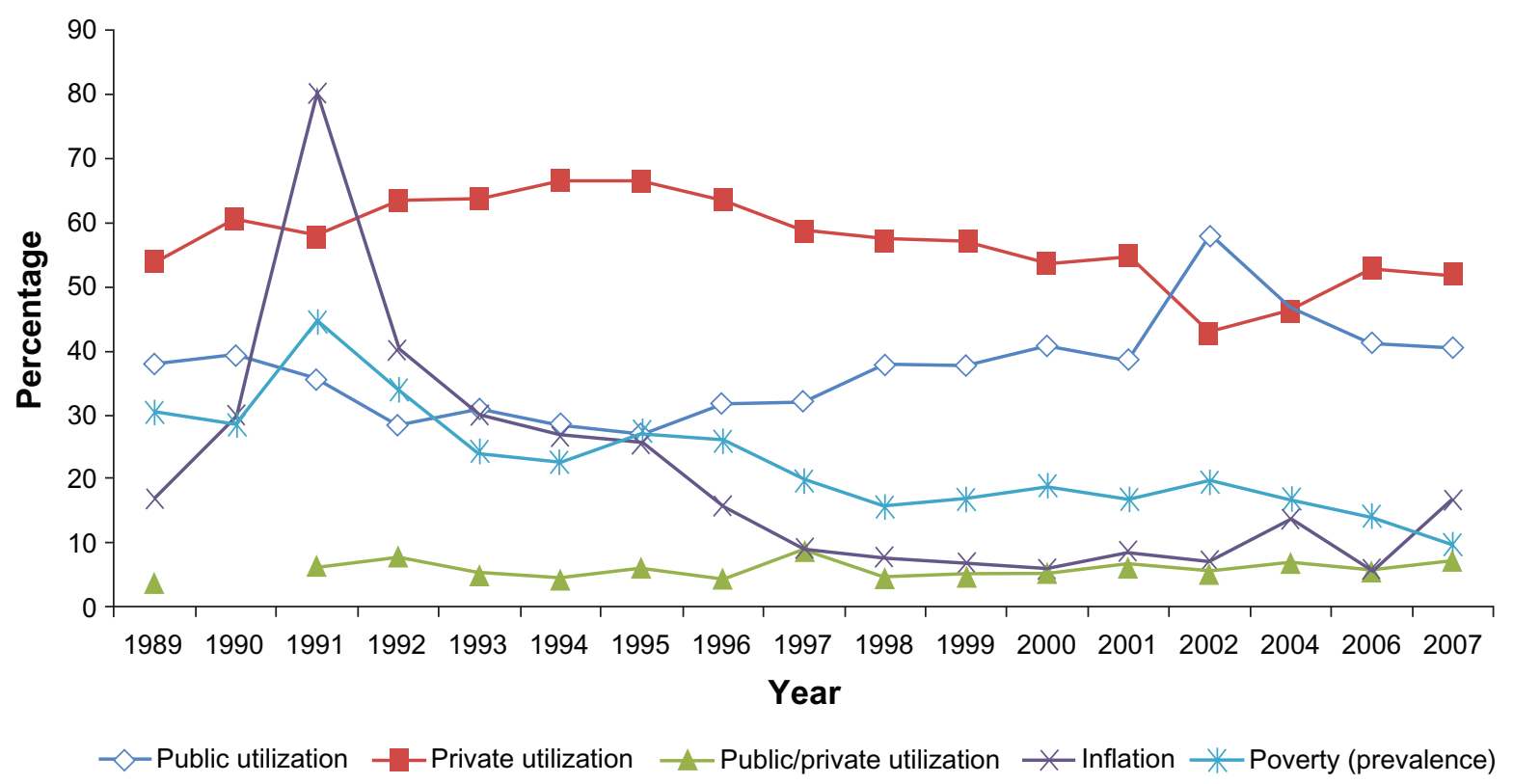

Figure 2 Public and private health care utilization, inflation and prevalence of poverty of Jamaicans, 1989-2007.

Note: "Public/private utilization" is the overall proportion of the Jamaican population seeking health care in both facilities. "Public utilization" and "Private utilization" are the proportion of those who do seek health care who choose public or private institutions respectively.

Data taken from Jamaica Survey of Living Conditions. ${ }^{21}$

Figure 4 presents information on public and private hospital health care utilization by Jamaicans, from reported patients who having had an illness. Overall, public hospital utilization among those in the poorest (poorest $20 \%$ ) and the second poor quintiles have seen an increased over the period (1991-2007) until those in quintiles $3-5$ that has seen a decline since 2002. In regards to private hospital utilization, quintile 1 has seen a decline since 2000 , and quintile 3 has an exponential reduction in 2002 over 2001, and a drastic increase in 2007 over 2006.
Table 1 presents information on discharge, average length of stay (in days), bed occupancy and visits to public hospitals. The mean public and private health care utilization by income quintile was presented in Table 2, and purchase of medication, hospitalization as well as mean expenditure on medication were shown in Table 3.

Per capita income quintiles and mean public-private health care service utilization are strongly correlated (Table 2 ): $\chi^{2}(\mathrm{df}=4)=35.68, P=0.005$, as income quintile changes from

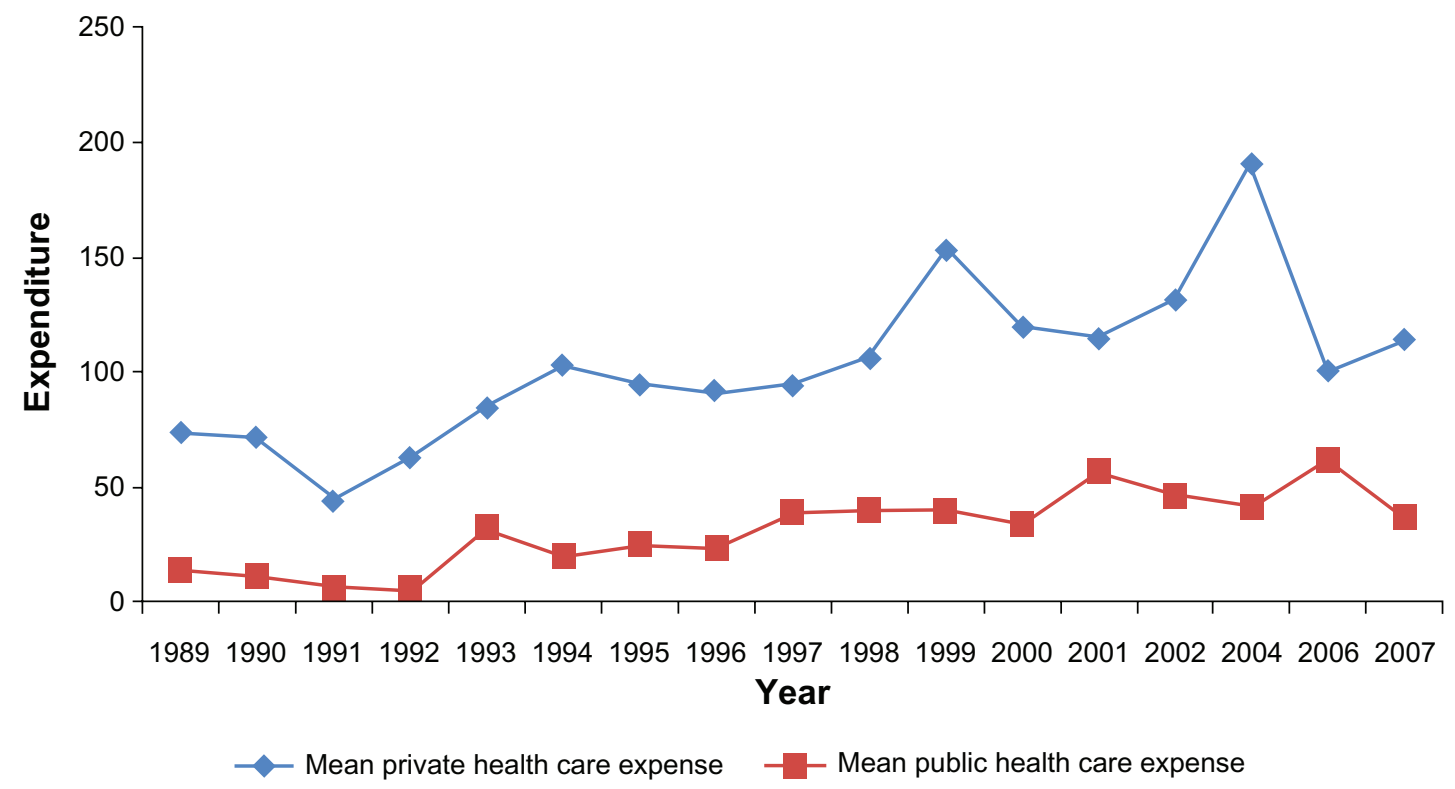

Figure 3 Mean expenditure on public and private health care services (in 1990 prices), 1989-2007. Notes: Data taken from Jamaica Survey of Living Conditions. ${ }^{21}$ 

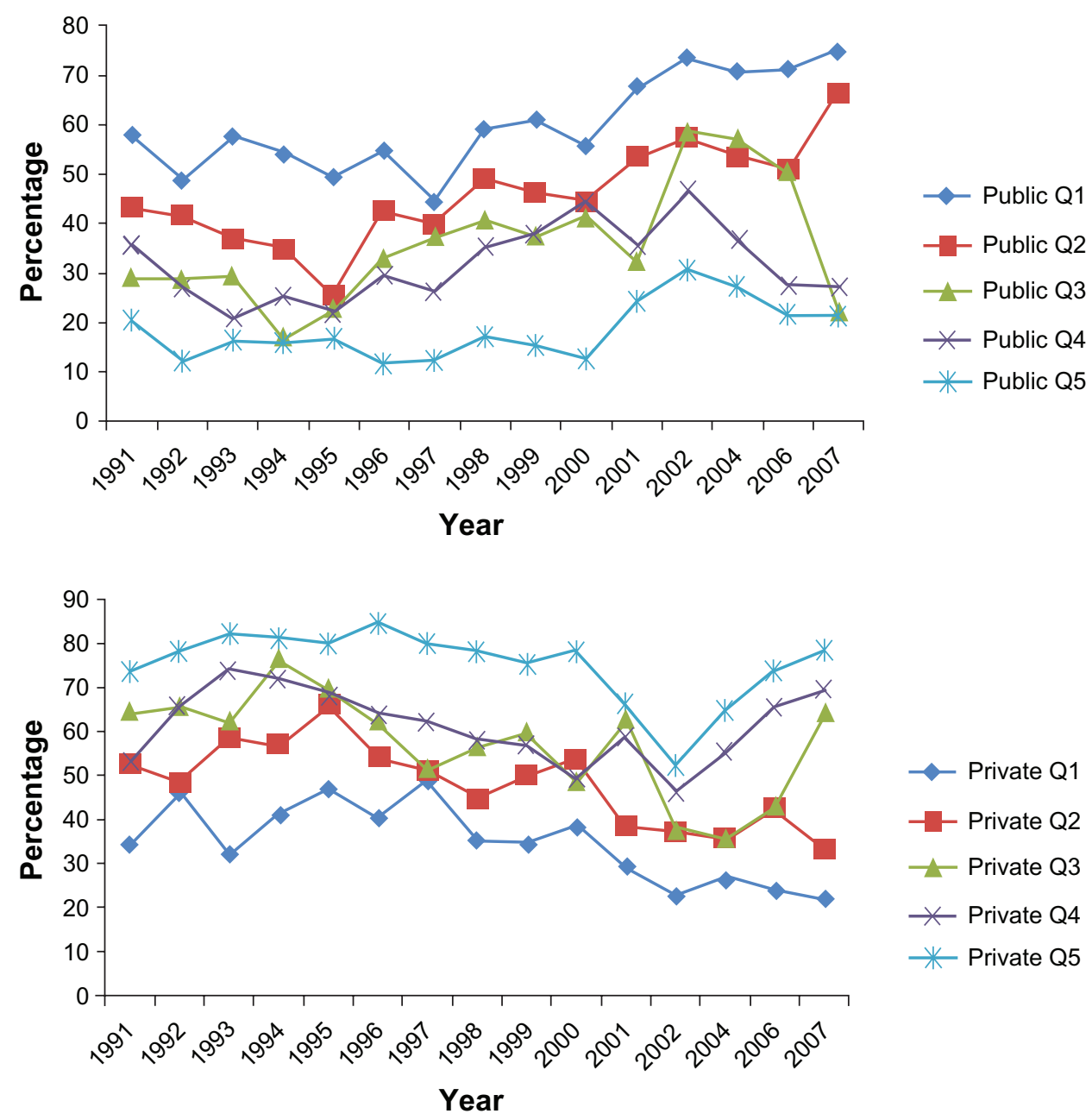

Figure 4 Hospital health care utilization from self-reported patients experiencing illness, by income quintile, 1991-2007.

Note: Public QI to Q5 denotes public hospital health care utilization. Private QI to Q5 denotes private hospital health care utilization. Data taken from Jamaica Survey of Living Conditions ${ }^{21}$ various issues.

poorest to wealthiest, people use substantially less public health care facilities compared to private health care services.

The utilization of public or private health care, purchasing of medication, and hospitalization as shown in Tables 2-4 have shown marginal increases over the research period. Public health care demand by Jamaicans increased from $38.0 \%$ in 1989 to $40.5 \%$ in 2007 and 2002 saw the highest percentage of utilization of those facilities (57.8\%) (Figure 2). Private health care demand, on the other hand, has declined from $54.0 \%$ in 1989 to $51.9 \%$ in 2007 and peaks at $66.7 \%$ in 1994 (Figure 2). The wide disparity that existed between public and private health care utilization in the 1990s has narrowed post 2001, and was even a switch to public health care utilization in 2002 (Figure 2).

Nevertheless, Jamaicans tend to be staying longer in public facilities post 2000 compared to the preceding period. Hospitalization rates increased in public health care facilities, and remained the same in private ones. The self-reported data of the JSLC reveals that public health care utilization has increased and this is supported by the Jamaica, Ministry of Health $(\mathrm{MoH})$ data, which show that public hospital discharges increased by $16.1 \%$ in 2004 over 2003 and by 118.9\% between 1997 and 2004 (Table 1). Comparatively, using $\mathrm{MoH}$ statistics, actual public hospitals visits between 1997 and 2004 increased by $29.7 \%$ (Table 1) and the JSLC statistics for the same period increased by $26.5 \%(P>0.05)$. This indicates that the JSLC data (on self-reported conditions) is a good proxy for actual conditions as the difference between the actual $(\mathrm{MoH})$ and the self-reported public health care visits (JSLC) is $3.2 \%$.

Measures of actual visits to public hospitals are reported in Jamaica, Ministry of Health, Annual Report and selfreported visits to the same institutions are collected by the Planning Institute of Jamaica and the Statistical Institute of Jamaica and reported in the Jamaica Survey of Living Conditions, JSLC. The former gathers information on some specific measures whereas the latter reveals more general health status and conditions of Jamaicans. 
Table I Patient occupancy details in Jamaican public hospitals, 1996-2007

\begin{tabular}{lllll}
\hline Year & Discharge & $\begin{array}{l}\text { Average length } \\
\text { of stay (days) }\end{array}$ & $\begin{array}{l}\text { Bed occupancy } \\
\text { rate (\%) }\end{array}$ & $\begin{array}{l}\text { Curative } \\
\text { visits }\end{array}$ \\
\hline 1996 & 145,656 & 5.7 & 56.1 & 546,933 \\
1997 & 153,101 & 5.8 & 57.3 & 598,004 \\
1998 & $158,85 \mid$ & 5.5 & 58.0 & 634,792 \\
1999 & 163,714 & 5.1 & 52.2 & 654,746 \\
2000 & 173,700 & 4.9 & 74.9 & 643,101 \\
2001 & 171,963 & 6.0 & 84.6 & 667,321 \\
2002 & 173,614 & 6.9 & 79.8 & 695,239 \\
2003 & 179,322 & 6.4 & 65.9 & 746,844 \\
2004 & 181,983 & 6.8 & 66.8 & 775,727 \\
2005 & 178,001 & 6.3 & 66.7 & 654,658 \\
$2006 *$ & 172,697 & 6.4 & 65.9 & 677,435 \\
$2007^{\dagger}$ & & & & \\
\hline
\end{tabular}

Notes: Data from: Jamaica, Ministry of Health, Planning and Evaluation Branch, ${ }^{22}$ various issues.

*Preliminary data; ${ }^{\dagger}$ No data are available.

Actual visits to public hospitals in 1997, for example, were $33.1 \%$ of the population (JAR), whereas the selfreported figure for the same period was $32.1 \%$ (JSLC), indicating no statistical association between the two data sources $(P>0.05)$. On the other hand, 2004 data show somewhat larger discrepancy between the studies, with $52.9 \%$ for actual visits (JAR) and $46.8 \%$ for reported visits (JSLC): There is no statistical relationship between the two dataset: $\mathrm{X}^{2}(\mathrm{df}=4)=3.79, P<0.05$.

Table 5 presents information on particular economic indicators (inflation, rate of gross domestic product, GDP, growth and prevalence of poverty) and some health indicators (such as health care utilization, self-reported illness, health insurance coverage, and health care seeking behavior). The Jamaican economy experienced an economic downturn during 1996-1999, where there were years of negative economic growth (Table 5). During the periods of negative economic growth, inflation rates were between 6 and $10 \%$, private health care utilization ranged between 57 and $64 \%$, and public health care utilization lies between 30 and $38 \%$.

Table 2 Mean health care service utilization in Jamaica by income quintiles, 1991-2000

\begin{tabular}{llll}
\hline Quintile $^{\mathrm{a}}$ & Public & Private & $\begin{array}{l}\text { Difference } \\
\text { Public-private }^{\mathrm{b}}\end{array}$ \\
\hline 1 & 54.5 & 40.4 & 14.0 \\
2 & 41.7 & 53.5 & -11.8 \\
3 & 32.8 & 62.4 & -29.7 \\
4 & 31.2 & 62.7 & -31.7 \\
5 & 16.5 & 78.7 & -62.2 \\
\hline
\end{tabular}

Notes: ${ }^{a}$ Quintile I $=$ Poorest $20 \% ; 5=$ Wealthiest $20 \%$; ${ }^{\text {bStrong }}$ correlation to quintile. $x^{2}(d f=4)=35.68, P=0.005$.

Data compiled from Jamaica Survey of Living Conditions, ${ }^{21}$ various issues.
Table 6 presents medical care seeking behavior, self-reported illness and mean number of days experienced illness by gender of respondents. Generally, females reported more illness, and sought medical care more than males: Health care seeking behavior of Jamaican females was mean $=59.4 \%( \pm 8.6 \%)$ compared to males $($ mean $=55.4 \% \pm 8.6 \%)$, correlation, $\mathrm{r}=0.897, P<0.0001$.

\section{Limitation of study}

The nature of the design of the study means that this research will not be able to establish causality, predictions, or forecast future events. In addition to the aforementioned issues, access (or inaccess) to health care is difficult to precisely determine, which means that this was not included, but this can play a role in influencing many of the findings which emerged. Another issue which plays a role in this study is the modification, expansion and building of new health care facilities, but these were not included in the current data analyses. Migration, population growth and knowledge of healthy lifestyle are critical issues which account for some of the differences which emerged, but these were not included.

\section{Discussion}

This research examined the association between the utilization of private and public health care services in Jamaica from the period 1993-2007. On average, 58 out of every 100 persons who are ill sought medical care. This low health seeking behavior is partly related to the public-private differentials in health care utilization. There has been greater use of the public health service which is reflected in the increase public hospital discharges and longer stay in these hospitals because of several interrelated internal and external economic factors.

Current study revealed that they experienced not only an economic downturn in 2002 over 2001, but also reduced health care seeking behavior of Jamaicans, increased prevalence of poverty, switching from private to public health care utilization, and when the economy expanded in 2004 over 2002 , poverty fell, health care seeking behavior increased, and even those in the poorest $20 \%$ switched from public to private health care utilization. During the aforementioned period (2001-2002), despite the increase in the use of the public health care utilization (49.4\%) compared to the reduction in private health care utilization (22.1\%), bed occupancy fell from $84.6 \%$ to $80.2 \%$ and average length of stay in public health care facilities increased to 6.9 days. In the time, the nominal amount spent by those who utilize private health care facilities increased by $21.4 \%$ compared to a $17.7 \%$ reduction in public health care expenditure. 
Table 3 Hospitalization costs, 1989-2007

\begin{tabular}{|c|c|c|c|c|c|c|c|c|}
\hline \multirow[t]{3}{*}{ Year } & \multirow{2}{*}{\multicolumn{2}{|c|}{$\begin{array}{l}\text { Medication } \\
\text { purchases (\%) }\end{array}$}} & \multirow{2}{*}{\multicolumn{2}{|c|}{$\begin{array}{l}\text { Hospitalization of those } \\
\text { seeking medical care (\%) }\end{array}$}} & \multicolumn{4}{|c|}{ Mean expenditure on health care visits } \\
\hline & & & & & \multicolumn{2}{|l|}{ Actual } & \multicolumn{2}{|c|}{ Fixed $(1990)^{a}$} \\
\hline & Public & Private & Public & Private & Public & Private & Public & Private \\
\hline 1989 & 18.6 & 90.5 & NA & NA & $\$ 11.00$ & $\$ 54.00$ & $\$ 14.00$ & $\$ 74.00$ \\
\hline 1990 & 10.9 & 72.1 & NA & NA & $\$ 10.90$ & $\$ 72.10$ & $\$ 11.00$ & $\$ 72.00$ \\
\hline 1991 & NA & NA & NA & NA & $\$ 10.90$ & $\$ 81.90$ & $\$ 6.00$ & $\$ 44.00$ \\
\hline 1992 & 8.9 & 58.9 & 5.1 & I.I & $\$ 13.90$ & $\$ 167.00$ & $\$ 5.00$ & $\$ 63.00$ \\
\hline 1993 & 15.9 & 79.9 & 6.9 & 0.5 & $\$ 115.00$ & $\$ 298.00$ & $\$ 33.00$ & $\$ 85.00$ \\
\hline 1994 & 21.4 & 75.6 & 4.6 & 0.8 & $\$ 91.00$ & $\$ 461.00$ & $\$ 20.00$ & $\$ 103.00$ \\
\hline 1995 & 16.4 & 81.9 & 6.0 & 0.2 & $\$ 130.00$ & $\$ 496.00$ & $\$ 25.00$ & $\$ 95.00$ \\
\hline 1996 & 19.1 & 78.0 & 5.1 & 0.5 & $\$ 148.00$ & $\$ 598.00$ & $\$ 23.00$ & $\$ 92.00$ \\
\hline 1997 & 22.0 & 74.3 & 7.4 & 1.8 & $\$ 283.00$ & $\$ 693.00$ & $\$ 39.00$ & $\$ 95.00$ \\
\hline 1998 & 19.7 & 76.6 & 7.6 & 0.9 & $\$ 315.00$ & $\$ 832.00$ & $\$ 40.00$ & $\$ 106.00$ \\
\hline 1999 & 18.5 & 77.0 & 7.4 & 0.9 & $\$ 339.00$ & $\$ 1301.00$ & $\$ 40.00$ & $\$ 154.00$ \\
\hline 2000 & 20.8 & 73.3 & 7.6 & 0.4 & $\$ 309.00$ & $\$ 1081.00$ & $\$ 34.00$ & $\$ 120.00$ \\
\hline 2001 & 20.0 & 76.9 & 7.3 & 0.4 & $\$ 546.00$ & $\$ 1103.00$ & $\$ 57.00$ & $\$ 115.00$ \\
\hline 2002 & 26.5 & 68.0 & 7.7 & 0.3 & $\$ 464.00$ & $\$ 1339.00$ & $\$ 46.00$ & $\$ 132.00$ \\
\hline 2003 & NA & NA & NA & NA & NA & $\mathrm{NA}$ & NA & NA \\
\hline 2004 & 19.1 & 74.3 & 7.1 & 0.7 & $\$ 489.00$ & $\$ 2278.00$ & $\$ 41.00$ & $\$ 191.00$ \\
\hline 2005 & NA & NA & NA & NA & NA & NA & NA & NA \\
\hline 2006 & 15.9 & 76.4 & 6.2 & 0.8 & $\$ 860.00$ & $\$ 1406.00$ & $\$ 62.00$ & $\$ 101.00$ \\
\hline 2007 & 13.7 & 80.3 & 5.8 & 0.3 & $\$ 539.90$ & $\$ 1679.50$ & $\$ 36.90$ & $\$ 114.20$ \\
\hline
\end{tabular}

Notes: NA = Data not available; Currency = Jamaican dollar. ${ }^{a}$ Given year's actual expenditure expressed in terms of 1990 prices. Aggregate costs are used for this table. Hospitalization columns refer to percentage of population. In 2003 and 2005, the Jamaica Survey of Living Conditions did not collect data on health matters including health care utilization.

Data compiled from Jamaica Survey of Living Conditions, ${ }^{21}$ various issues.

The income differential among socioeconomic hierarchies influences the mean public-private utilization of health care because as income increases the use of private health care service increases. Therefore, the wealthier Jamaicans with greater income utilize $62.2 \%$ more private health facilities than the poorest Jamaicans who use $14 \%$ more of the public health care facilities. The differences between public and private health care utilization in Jamaica is clearly more than merely (differences is about income differential that explain what is now a public-private health care utilization differen-

Table 4 Labor force indicators by gender, 1990-2007

\begin{tabular}{|c|c|c|c|c|c|c|}
\hline \multirow[t]{2}{*}{ Year } & \multicolumn{3}{|l|}{ Male } & \multicolumn{3}{|l|}{ Female } \\
\hline & $\begin{array}{l}\text { Labor force } \\
\text { (000's) }\end{array}$ & $\begin{array}{l}\text { Employed labor } \\
\text { force (000's) }\end{array}$ & $\begin{array}{l}\text { Unemployment } \\
\text { rate }(\%)\end{array}$ & $\begin{array}{l}\text { Labor force } \\
\text { (000's) }\end{array}$ & $\begin{array}{l}\text { Employed labor } \\
\text { force (000's) }\end{array}$ & $\begin{array}{l}\text { Unemployment } \\
\text { rate }(\%)\end{array}$ \\
\hline 1990 & 564.6 & 896.3 & 15.3 & 494 & 513.1 & 9.1 \\
\hline |99| & 571.8 & 518.1 & 9.4 & 500.7 & 389.6 & 22.2 \\
\hline 1992 & 570.1 & 516 & 9.5 & 504.8 & 389.7 & 22.8 \\
\hline 1993 & 571.3 & 509.2 & 10.9 & 511.7 & 397.1 & 22.4 \\
\hline 1994 & 574.8 & 519.9 & 9.6 & 515.8 & 403.2 & 21.8 \\
\hline 1995 & 617.9 & 551 & 10.8 & 532.2 & 412.4 & 22.5 \\
\hline 1996 & 614.6 & 553.3 & 10 & 528.2 & 406.5 & 23.1 \\
\hline 1997 & 613.8 & 549 & 10.6 & 520 & 397.9 & 23.5 \\
\hline 1998 & 614.3 & 552.9 & 10 & 514.2 & 400.7 & 22.1 \\
\hline 1999 & 611.7 & 550.3 & 10 & 507.4 & 393.6 & 22.4 \\
\hline 2000 & 615 & 552.4 & 10.2 & 490.3 & & 22.3 \\
\hline 2001 & 618.1 & 554.8 & 10.3 & 486.7 & 384.7 & 21 \\
\hline 2002 & 618.4 & 552.8 & 10.6 & 506.1 & 401.6 & 20.7 \\
\hline 2003 & 611.1 & 552.3 & 9.7 & 487.7 & 402.3 & 17.6 \\
\hline 2004 & 663.5 & 610.9 & 7.9 & 531.3 & 444.3 & 16.4 \\
\hline 2005 & 661.9 & 611.4 & 7.6 & 529.1 & 445.6 & 15.8 \\
\hline 2006 & 695.6 & 646.8 & 7 & 557.5 & 476.9 & 14.5 \\
\hline 2007 & 699.1 & 656.1 & 6.2 & 562.2 & 480.8 & 14.5 \\
\hline
\end{tabular}

Data from Economic and Social Survey of Jamaica. ${ }^{33}$ 
Table 5 Inflation, public-private health care service utilization, incidence of poverty, illness and prevalence of population with health insurance (in per cent), 1988-2007

\begin{tabular}{|c|c|c|c|c|c|c|c|c|}
\hline \multirow[t]{2}{*}{ Year } & \multirow[t]{2}{*}{ Inflation (\%) } & \multirow{2}{*}{$\begin{array}{l}\text { GDP } \\
\text { growth (\%) }\end{array}$} & \multirow[t]{2}{*}{ Poverty (\%) } & \multirow[t]{2}{*}{ Illness (\%) } & \multirow{2}{*}{$\begin{array}{l}\text { Health } \\
\text { insurance (\%) }\end{array}$} & \multirow{2}{*}{$\begin{array}{l}\text { Seeking } \\
\text { medical care } \text { ca) }^{\mathrm{e}} \%\end{array}$} & \multicolumn{2}{|c|}{$\underline{\text { Utilization }}$} \\
\hline & & & & & & & Public & Private \\
\hline 1989 & 17.2 & 6.5 & 30.5 & 16.8 & 8.2 & 54.6 & 42.0 & 54.0 \\
\hline 1990 & 29.8 & 5.7 & 28.4 & 18.3 & 9.0 & 38.6 & 39.4 & 60.6 \\
\hline 199| & 80.2 & 0.4 & 44.6 & 13.7 & 8.6 & 47.7 & 35.6 & 57.7 \\
\hline 1992 & 40.2 & 1.4 & 33.9 & 10.6 & 9.0 & 50.9 & 28.5 & 63.4 \\
\hline 1993 & 30.1 & 1.2 & 24.4 & 12.0 & 10.1 & 51.8 & 30.9 & 63.8 \\
\hline 1994 & 26.8 & I.I & 22.8 & 12.9 & 8.8 & 51.4 & 28.8 & 66.7 \\
\hline 1995 & 25.6 & 0.5 & 27.5 & 9.8 & 9.7 & 58.9 & 27.2 & 66.4 \\
\hline 1996 & 15.8 & -1.3 & 26.1 & 10.7 & 9.8 & 54.9 & 31.8 & 63.6 \\
\hline 1997 & 9.2 & -2.0 & 19.9 & 9.7 & 12.6 & 59.6 & 32.1 & 58.8 \\
\hline 1998 & 7.9 & -0.5 & 15.9 & 8.8 & 12.1 & 60.8 & 37.9 & 57.3 \\
\hline 1999 & 6.8 & -0.4 & 16.9 & 10.1 & 12.1 & 68.4 & 37.9 & 57.1 \\
\hline 2000 & 6.1 & 0.8 & 18.9 & 14.2 & 14.0 & 60.7 & 40.8 & 53.6 \\
\hline 2001 & 8.8 & 1.5 & 16.9 & 13.4 & 13.9 & 63.5 & 38.7 & 54.8 \\
\hline 2002 & 7.2 & I.I & 19.7 & 12.6 & 13.5 & 64.1 & 57.8 & 42.7 \\
\hline 2003 & 13.8 & 2.3 & 19.1 & NA & NA & NA & NA & NA \\
\hline 2004 & 13.7 & 0.9 & 16.9 & I I.4 & 19.2 & 65.1 & 46.3 & 46.4 \\
\hline 2005 & 12.6 & 1.4 & 14.8 & NA & NA & NA & NA & NA \\
\hline 2006 & 5.7 & 2.5 & $\mid 4.3$ & 12.2 & 18.4 & 70.0 & 41.3 & 52.8 \\
\hline 2007 & 16.8 & 1.2 & 9.9 & 15.5 & 21.2 & 66.0 & 40.5 & 51.9 \\
\hline
\end{tabular}

Notes: NA = data not available. alnflation is measured point-to-point at the end of each year (December to December), based on Consumer Price Index; ${ }^{b} \mathrm{GDP}$ growth is

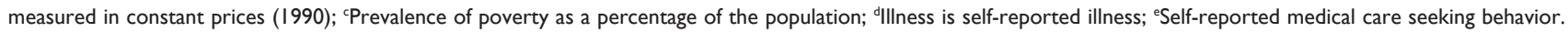
Percentage denotes of the population. In 2003 and 2005, the Jamaica Survey of Living Conditions did not collect data on health matters including health care utilization.

Data from Statistical Digest, ${ }^{34}$ Jamaica Survey of Living Conditions, ${ }^{21}$ Economic and Social Survey of Jamaica, ${ }^{33}$ various issues.

tial) this section not clear. Following the economic downturn in the Jamaican economy between 1996 and 1999, there was still a preference for private health care utilization, but some switching occurred towards public health care facilities, and this was associated with low reports of illnesses and inflation. While there has been a greater percentage increase in public health care cost (from 1989-2007) compared to private health care cost at 1990 prices, and the substantially greater cost of private health care services, Jamaicans still prefer the private health care system. The findings show that even in years of high inflation (1990-1995), the average private health care utilization was almost twice that of the public health care utilization. Furthermore, private health care utilization in the aforementioned years was even greater than in periods of low inflation (Table 3). Embedded in this preference are psychosocial factors associated with public versus private health care system (ie, treatment by health care professionals, average time taken before treatment, physical ambiance, professionalism of heath care practitioners, and social grace differences).

Jamaicans' demand for public health care increased by 2.5\% between 1989-2007 while the demand for private health care declined by $3 \%$ during the same period; and the annual population rate was about $0.5 \%$. These negligible shifts in private-public demand which closed the huge gap of the 1990s, occurred because of an increase in poverty. There were other changes such as the $6.5 \%$ increase in the purchase of medication by users of the public health system between 2000 and 2001 compared to the purchase of medication by private users which declined by $8.9 \%$. The decline in private use after 2002 compared to the 1990s does not obscure the fact that Jamaicans have a preference for private health care services. This increase demand of private health care has occurred despite the $154 \%$ increase in the cost of health care services in the private sector and relatively high inflation over the study period (mean $=20.5 \% \pm 18.5 \%$ ). The harsh economic climate, therefore, has increased and stabilized the rate of hospitalization in public and private facilities respectively. But another issue which accounts for this increase is the increase in education level of population, increased urbanization of the population, intervention and healthy lifestyle campaign, knowledge and exposure of the population, and the particular situations such as the outbreak of influenza. Another issue is health-gender inequality.

The current study revealed that on average males reported less illness and are likely to utilize less health care services compared to females. A qualitative study by Ali and de Muynck, ${ }^{16}$ in Pakistan, found that illness and its severity are responsible for male street children's willingness to utilize medical care facilities. Previous studies in developing nations 
Table 6 Seeking medical care, self-reported illness, and gender composition of those who report illness and seek medical care in Jamaica (in percentage), 1988-2007

\begin{tabular}{|c|c|c|c|c|c|c|}
\hline \multirow[t]{3}{*}{ Year } & \multicolumn{3}{|l|}{ Male } & \multicolumn{3}{|l|}{ Female } \\
\hline & $\begin{array}{l}\text { Medical care } \\
\text { seeking }\end{array}$ & $\begin{array}{l}\text { Self-reported } \\
\text { illness }\end{array}$ & $\begin{array}{l}\text { Mean days } \\
\text { in illness }\end{array}$ & $\begin{array}{l}\text { Medical care } \\
\text { seeking }\end{array}$ & $\begin{array}{l}\text { Self-reported } \\
\text { illness }\end{array}$ & $\begin{array}{l}\text { Mean days in } \\
\text { illness }\end{array}$ \\
\hline & $\%$ & $\%$ & $\%$ & $\%$ & $\%$ & $\%$ \\
\hline 1989 & 44.7 & 15 & 10.6 & 52.8 & 18.5 & II.I \\
\hline 1990 & 37.9 & 16.3 & 10.2 & 39.2 & 20.3 & 10.2 \\
\hline 1991 & 48.5 & 12.1 & 10 & 47.4 & 15 & 10.3 \\
\hline 1992 & 49 & 9.9 & 10.7 & 52.5 & 11.3 & 10.9 \\
\hline 1993 & 48 & 10.4 & 10.7 & 54.7 & 13.5 & 10.1 \\
\hline 1994 & 49 & 11.6 & 10.3 & 53.4 & 14.3 & 10.4 \\
\hline 1995 & 59 & 8.3 & 10.6 & 58.9 & 11.3 & 10.7 \\
\hline 1996 & 50.5 & 9.7 & 10 & 58.5 & 11.8 & 11 \\
\hline 1997 & 60 & 8.5 & 11 & 59.3 & 10.9 & 10 \\
\hline 1998 & 57.8 & 7.4 & 11 & 62.8 & 10.1 & 11 \\
\hline 1999 & 64.2 & 8.1 & 11 & 71.1 & 12.2 & 11 \\
\hline 2000 & 57.4 & 12.4 & 9 & 63.2 & 16.8 & 9 \\
\hline 2001 & 56.3 & 10.8 & 9 & 68.2 & 15.9 & 10 \\
\hline 2002 & 62.1 & 10.4 & 10 & 65.3 & 14.6 & 10 \\
\hline 2003 & NA & NA & NA & NA & NA & NA \\
\hline 2004 & 64.2 & 8.9 & II & 65.7 & 13.6 & 10 \\
\hline 2005 & NA & NA & NA & NA & NA & NA \\
\hline 2006 & 71.7 & 10.3 & 9.7 & 68.8 & 14.1 & 10 \\
\hline 2007 & 62.8 & 13.1 & 10.6 & 68.1 & 17.8 & 9.3 \\
\hline
\end{tabular}

Notes: NA = data not available. In 2003 and 2005, the Jamaica Survey of Living Conditions did not collect data on health matters including health care utilization. Data from JSLC, ${ }^{21}$ various issues.

have shown that health care seeking behavior and utilization are influenced by illness, severity, and if illness is likely to result in the separation from ones job. ${ }^{17-20}$ JSLC shows health care utilization on average in Jamaica is a feminized phenomenon (Table 6), ${ }^{21}$ which is similar to other developing countries such as Pakistan, India, South Africa and other African nations. ${ }^{16-21}$ Embedded in the literature is an explanation for the gender difference number of discharges and visits to public hospitals using the Ministry of Health data. ${ }^{22}$ Hence, the number of people who have been discharged and visits to public hospitals would reflect mostly females as males are reluctant to visit health care institution for fear of being labeled weak.

Male's reluctance to seek help for health matters are embedded in the culture that associate illness with weakness. ${ }^{23}$ This position is not only a Caribbean phenomenon as Doyal ${ }^{24}$ opined that males are socialized not to overtly exhibit pain and emotions such as fear about illness. Illness therefore is a feminized phenomenon in many societies, and this prevents males from seeking a medical practitioner. The issue of males' unwillingness to seek medical care and utilize health services appears to be a practice in Western nations. ${ }^{25-28}$ This unwillingness is influenced by hegemonic masculinity which is the socially supported and dominant masculinity that inform normative male behavior and unequal gender practices seen in the subordination of women. This dominant masculinity which is associated with power, authority, heterosexism and physical toughness and legitimizes patriarchy not only subordinates femininities but also other masculinities in the society's gendered hierarchy. ${ }^{29}$

Outside of the health-gender disparity which emerged from the current findings, which is not atypical, there is also the social hierarchy-health disparity. The World Health Organization (WHO) opined that $80 \%$ of chronic illnesses were in low and middle income countries and that $60 \%$ of global mortality is caused by chronic illness ${ }^{30}$ suggesting that illness interfaces with poverty and other socioeconomic challenges. This, then, provides an explanation for the low private health care utilization among the poor, and is also a justification for lower health care utilization among this social stratum in periods of high inflation. According to Marmot, poverty and illness are associated, as well as poverty and poor physical environment, low nutritional intake, and health care seeking behavior all influence illness. ${ }^{31}$ Thus, health care utilization to public facilities is sought by many people in developing countries because of inaffordability, poverty and low material resources. A study by Peters et $\mathrm{a} \mathrm{l}^{32}$ found that the poor in developing nations demand less health care services than those in better-off-countries, which is concurred by the current study. 
Jamaica is among the developing nations, and so the current study provides pertinent information on health care utilization disparities among people that exist in a similar society. The current work showed that the average amount spent for public health care utilization costs were substantially lower than that for private health care utilization costs, which is an indication of those who attend each facility. Although public health care services in Jamaica are exponentially cheaper than that in private health care facilities, some people are still unable to attend because the amount that they earn is marginally more than that which is adequate for food, shelter, clothing and schooling for their children. This means that there is a choice to delay health care for the aforementioned issues, except if it is child who is ill, at the perilous price. Thus, it is not surprising that the poor experienced greater mortality, and higher premature mortality than the wealthy. ${ }^{23}$ Poverty does not only mean greater mortality, low nutritional intake, physical environment and low health care utilization, but it also provides an explanation for lawfulness, illegality, criminality, lower educational attainment, and social opportunities.

Winfree and Abadinsky ${ }^{35}$, used the work of Herrnstein and Murray ${ }^{36}$ established that there is an association between intelligent quotient (IQ) and criminality. Herrnstein and Murray ${ }^{36}$ acknowledge the possibility that high IQ could provide "some protection against lapsing into criminality for people who are otherwise at risk". They further opined that, "among the most firmly established facts about criminal offenders is that their distribution of IQ scores differs from that of the population at large. The relationship of IQ to criminality is especially pronounced in the small fraction of the population, primarily young men, who constitute the chronic criminal, that account for a disproportionate amount of crime". ${ }^{36}$ The aforementioned literature omitted poor, suggesting that unlawfulness; criminality, low educational attainment, and material deprivation are among barriers which account for low health care utilization. The activities of the poor are among the justifications why they opt not to utilize the formal health care system for initial ill-health. The official health care utilization data, therefore, is not accounting for utilization of homecare, healers, and informal doctor visits, which are frequently used by the poor because of financial and material deprivation.

The official data of public hospital visits recorded by the $\mathrm{MoH}^{22}$ and the JSLC ${ }^{21}$ approximates the self reported data of public hospital visits. The quality of the JSLC survey data as validated by the $\mathrm{MoH}$ quantitative values, indicate the validity of using subjectivity in health measurement. The $\mathrm{MoH}$ data provide other statistics (such as bed occupancy, average length of stay in hospitals, discharge) which add the subjective measures offered by the JSLC. While care should be made in interpreting the period used for MoH and JSLC, the official data provides useful insights into the public-private differentials in sources of health care utilization among Jamaicans as well as validity, a period in the objective-subjective measure of the two data sources. While it is true that the pertinent information emerged from the current research, with the absence of the proportion of people who visit healers, use home remedies and other forms of non-formal medical intervention during the studied period, thus hinder valuable information that could have been used to understand the trends which were highlighted in this research.

\section{Conclusion}

Internal and external economic conditions influence the use of private and public health care services in Jamaica. Although the percentage increase in the cost of public health care is more than the percentage increase in the cost of private health care, the actual cost to use the public health care system is still much cheaper than using the private system. Economic wellbeing appears to influence the use of health care services in Jamaica, although there is a tendency for people to use the private health care system rather than the public health care facility except among the poor and poorest $20 \%$. Despite the harsh economic conditions, there is a strong preference for the private system because the gap in the public-private differential has decreased significantly. However, these same economic conditions have led to a marginal increase in public use and a marginal decrease in private use. The increase in public use is evident in greater public hospitals visits, greater bed occupancy and longer stay in public hospitals. The official data on health care utilization approximates self reported health care utilization so the official data are useful in understanding the public-private differentials in Jamaica.

Another issue which emerged in this study is the quality of sample survey data collected by the Planning Institute of Jamaica and the Statistical Institute of Jamaica. The findings of this study highlight the high degree of accuracy of selfreported data compared with those of the hospital records (collected by the Ministry of Health). Embedded in the finding is the validity of using subjective health (self-reported health matters) to represent quantitative health.

Clearly, health care utilization in Jamaica is a complex phenomenon. During the periods of high inflation and poverty, private health care utilization was greater than in periods of low inflation, and the cost of public health care services were on average at least one half of that of private 
health care services. However, the purchase of medication among those who attended public health care facilities was lower in high inflationary period until for those who attended private care facilities.

\section{Disclosure}

The authors have no competing interests to report.

\section{References}

1. World Health Organization. Health amid a financial crisis: a complex diagnosis. Bulletin of the World Health Organization. 2009; 874-875.

2. Paes de Barros R, Ferreira FHG, Vega JRM, et al. Measuring inequality of opportunities in Latin America and the Caribbean. World Bank, Washington DC. 2009;47-50.

3. Pan American Health Organization. Equity and health - views from the Pan American Sanitary Bureau. Occasional Publication No. 8. Washington, DC. 2001.

4. Regidor E, Martinez D, Calle ME, Astasio P, Ortega P, Dominquez V. Socioeconomic patterns in the use of public and private services and equity in health care. BMC Health Services Research. 2008;8:183

5. Singh $\mathrm{CH}$. The public-private differential in health care and health care cost in India: the case of inpatients. J Public Health. 2009;17:401-407.

6. van Doorslaer E, Clarke P, Savage E, Hall J. Horizontal inequities in Australia's mixed public/private health care system. Health Policy. 2008;86:97-108.

7. Moorin RE, Holman CDJ. Does federal health care policy influence switching between the public and private sectors in individuals? Health Policy. 2006;79:284-295.

8. Brekke KR, Sørgard L. Public versus private health care in a national health service. Health Economics. 2007;16:579-601.

9. Bhatia S, Natshen A. Should Canadian physicians support parallel private health care? Canadian Med Ass J. 2005;173:901-902.

10. Zwi AB, Brugha R, Smith E. Private health care in developing countries. BMJ. 2001;323:463-464.

11. Sinclair K. The spatial patterns of utilization in primary health care facilities in Kingston. B.A. Thesis, University of the West Indies, Jamaica. 1985:47.

12. Paul TJ, Maharaj SR. The prevalence of health insurance in a Jamaican suburb and its correlations with service utilization. West Ind Med J. 1989;38:238-240.

13. Vom Eigen KM. Science and spirit: Health care utilization in rural Jamaica. Dissertation Abstracts International. 1992;53:868.

14. Barr DA. Ethics in public health research: A research protocol to evaluate the effectiveness of public-private partnerships as a means to improve health and welfare systems worldwide. Am J of Public Health. 2007;97:19-25.

15. Rosenberg L. Comparative effectiveness research: Making it work for those we serve. J Behav Health Serv Res. 2009;36:283-284.
16. Ali M, de Muynck A: Illness incidence and health seeking behaviour among street children in Pawalpindi and Islamabad, Pakistan - qualitative study. Child: Care, Health and Development. 2005;31:525-532.

17. Taff N, Chepngeno G: Determinants of health care seeking for children illnesses in Nairobi slums. Trop Med and Int Health. 2005;10: 240-245.

18. Sudha G, Nirupa C, Rajasakthivel M, et al: Factors influencing the care-seeking behavior of chest symptomatic: a community-based study involving rural and urban population in Tamil Nadu, South India. Trop Med and Int Health. 2003;8:336-341.

19. Stekelenburg J, Jager B, Kolk P, et al. Health care seeking behaviour and utilization of traditional healers in Kalabo, Zambia. Health Policy. 2005;71:67-81.

20. Case A, Menendex A, Ardington C: Health seeking behaviour in Northern KwaZulu-Natal. CSSR Working Paper No. 116. Cape Town: Centre for Social Science Research, University of Cape Town; 2005.

21. Planning Institute of Jamaica (PIOJ), Statistical Institute of Jamaica (STATIN). Jamaica Survey of Living Conditions, 1989-2007. Kingston, Jamaica: PIOJ and STATIN; 1989-2008.

22. Jamaica, Ministry of Health (MoH). Annual Report, 1989-2006. Kingston: Planning and Evaluation Branch, MoH;1990-2007.

23. Chevannes B. Learning to be a man: Culture, socialization and gender identity in five Caribbean communities. Kingston, Jamaica: The Univer. of the West Indies Press; 2001.

24. Doyal L. Gender equity in health: Debates and dilemmas. Soci Sci and Medicine 2000;51:931-939.

25. Smith JA, Braunack-Mayer A, Wittert G. What do we know about men's help-seeking and health service use: The Medical J of Australia 2006;184:81-83.

26. White A, Banks I. Help seeking in men and the problems of late diagnosis In: Kirby R, Carson C, Kirby M, Farah R, editors. Men's health; 2004

27. Galdas P, Cheater F, Marshall P. Men and health-seeking behaviour: Literature review. J of Advanced Nursing. 2005;49:616-623.

28. O'Brien R, Hunt K, Hart G. It's caveman stuff, but that is to a certain extent how guys still operate: Men's accounts of masculinity and help seeking. Social Science and Medicine. 2005;61:503-516.

29. Connell RW. Masculinities. St Leonards, new South Wales: Allen \& Unwin; 1995

30. World Health Organization (WHO). Preventing Chronic Diseases a vital investment. WHO Global report. WHO Geneva. 2005.

31. Marmot M. The influence of income on health: Views of an Epidemiologist. Does money really matter? Or is it a marker for something else? Health Affairs. 2002;21:31-46.

32. Peters DH, Garg A, Bloom G, et al. Poverty and access to health care in developing countries. Ann NY Acad Sci. 2008;1136:161-171.

33. Planning Institute of Jamaica (PIOJ). Economic and Social Survey of Jamaica, 1980-2007. Kingston: PIOJ; 1981-2008.

34. Statistical Institute of Jamaica (STATIN). Statistical Digest, 1970-1989. Kingston; STATIN; 1971-1990.

35. Winfree L Jr, Abadinsky H. Understanding Crime: Theory and practice. Belmont, CA: Wadsworth; 2003.

36. Herrnstein RJ, Murray C. The bell curve: Intelligence and class structure in American life. New York: Free Press; 1994
Patient Related Outcome Measures

\section{Publish your work in this journal}

Patient Related Outcome Measures is an international, peer-reviewed, open access journal focusing on treatment outcomes specifically relevant to patients. All aspects of patient care are addressed within the journal and practitioners from all disciplines are invited to submit their work as well as healthcare researchers and patient support groups. Areas covered will

\section{Dovepress}

include: Quality of life scores; Patient satisfaction audits; Treatment outcomes that focus on the patient; Research into improving patient outcomes; Hypotheses of interventions to improve outcomes; Short communications that illustrate improved outcomes; Case reports or series that show an improved patient experience; Patient journey descriptions or research. 